

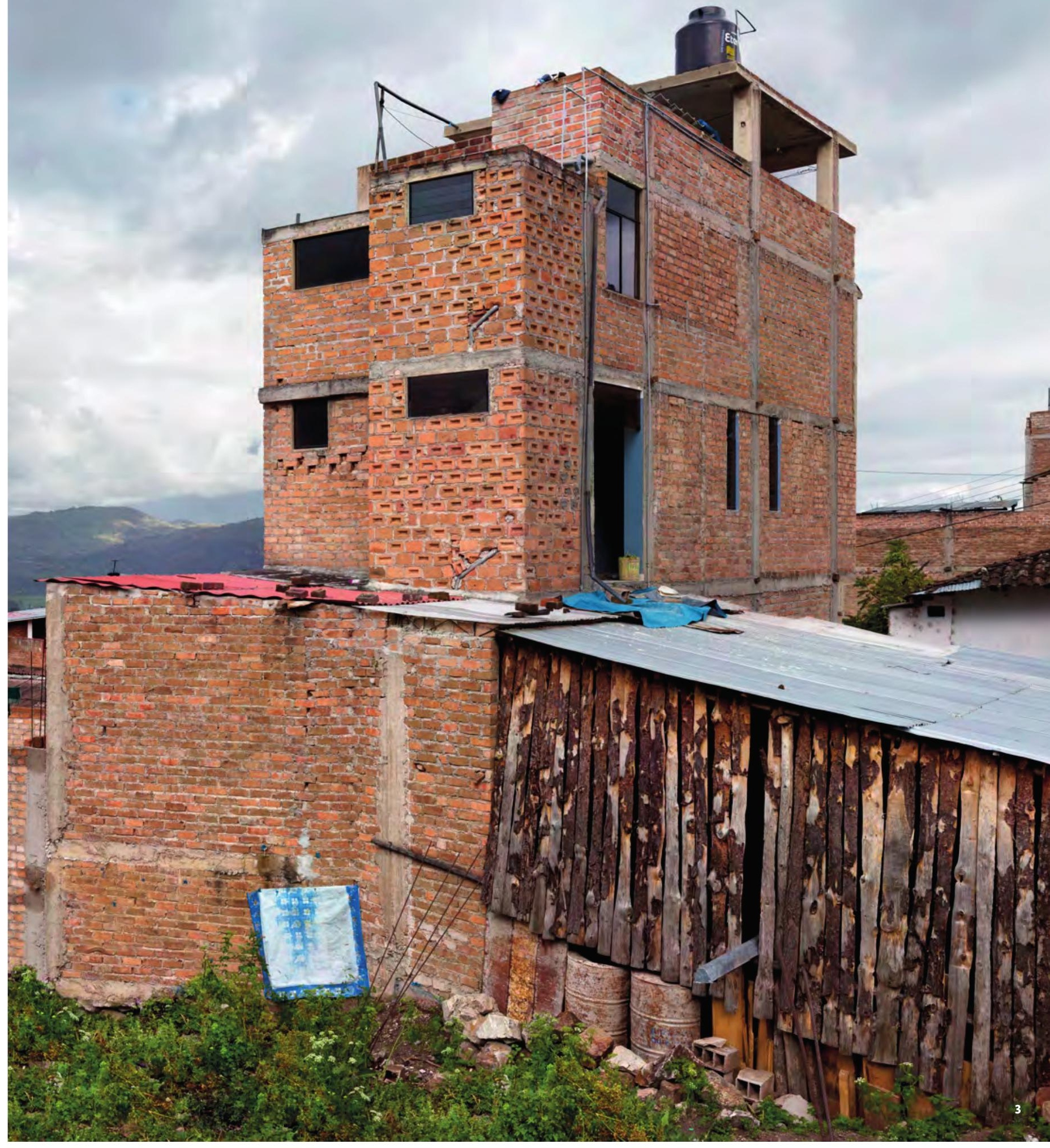




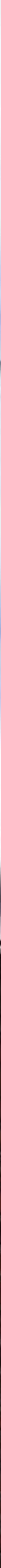




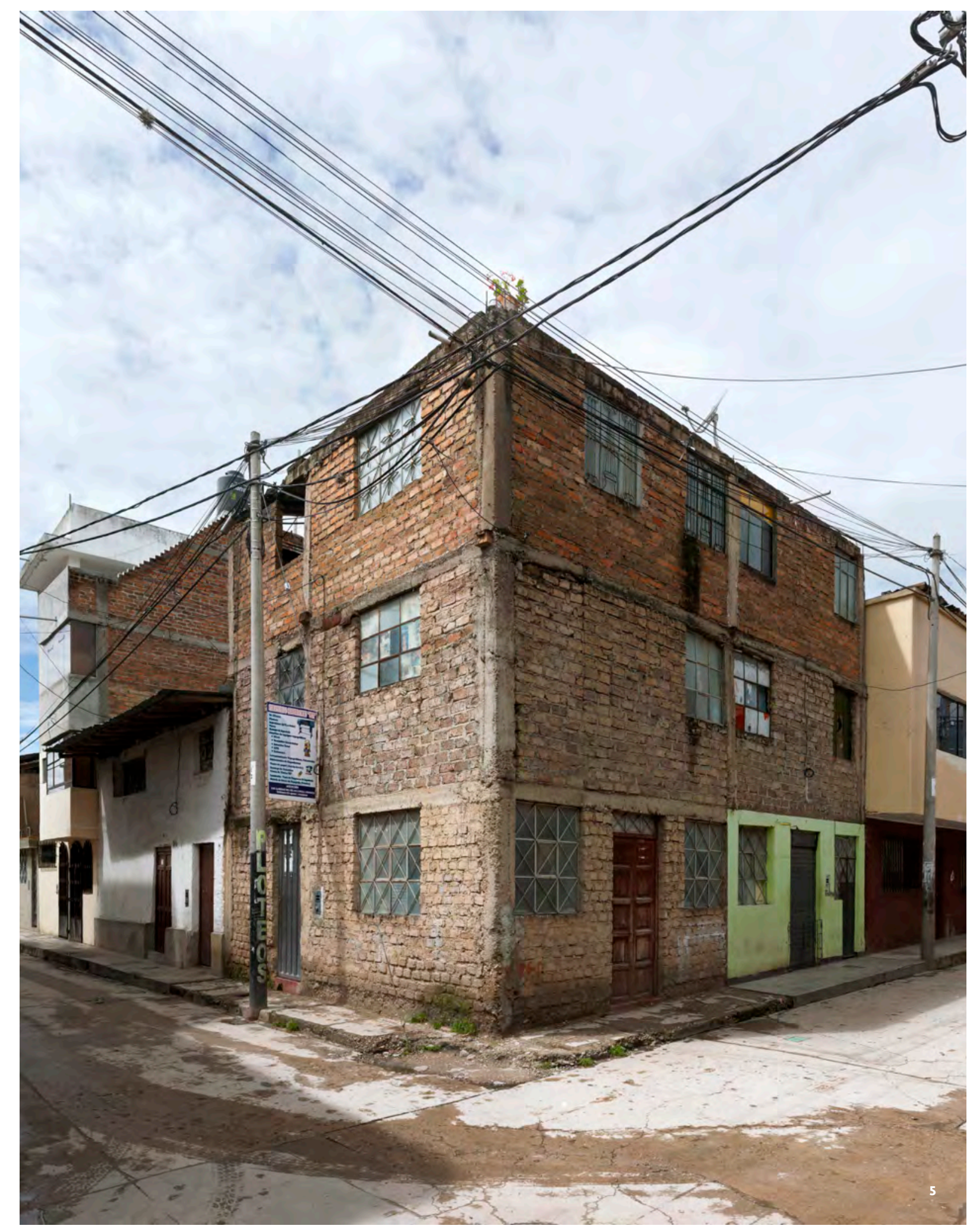

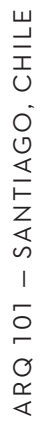

4-5 Cajamarca, Perú.

(c) Edi Hirose 


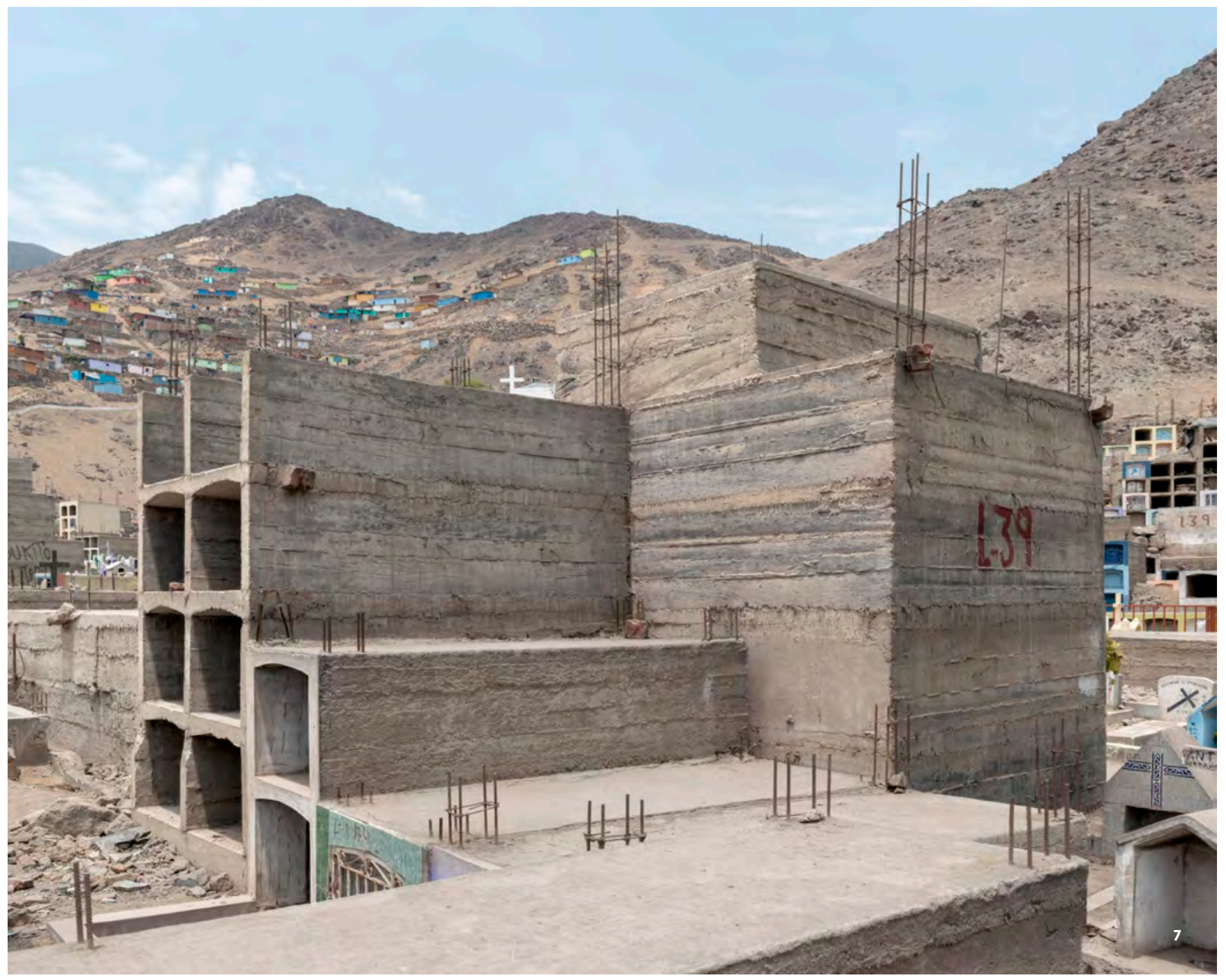

6 Cajamarca, Perú.

(c) Edi Hirose

7 Lima, Perú.

(c) Edi Hirose

\section{Edi Hirose}

$<$ edihirose@gmail.com>

Graduated from the Antonio Gaudí photograph institute, Lima. His latest work addresses the consequences of the Peruvian landscape, affected by last decade's economic growth. His work has been exhibited at the São Paulo Biennial 2012, Estambul Biennial 2013, Lima Photography Biennial 2012 and 2014. In 2017 was chosen by the Magnum Foundation Fund to develop his Ananay project, on informal mining in Puno. His work is part of the Société Générale Collection, MoMA, Venancio Blanco, Teo Millán, Blanton Museum, MALI and private collections. 